\title{
Spatial and temporal variations of Norwegian geohazards in a changing climate, the GeoExtreme Project
}

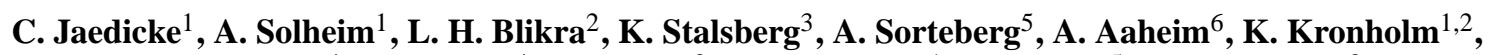

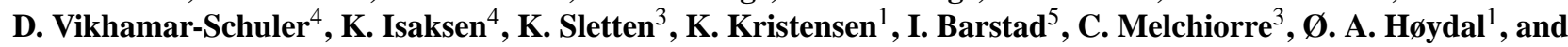 \\ H. Mestl ${ }^{6}$ \\ ${ }^{1}$ Norwegian Geotechnical Institute NGI, Oslo, Norway \\ ${ }^{2}$ International Centre for Geohazards ICG, Oslo, Norway \\ ${ }^{3}$ Geological Survey of Norway, Trondheim, Norway \\ ${ }^{4}$ Norwegian Meteorological Institute met.no, Oslo, Norway \\ ${ }^{5}$ Bjerknes Centre for Climate Research, BCCR, Bergen, Norway \\ ${ }^{6}$ CICERO, Centre for International Climate and Environmental Research, Oslo, Norway
}

Received: 9 October 2007 - Revised: 26 March 2008 - Accepted: 7 July 2008 - Published: 19 August 2008

\begin{abstract}
Various types of slope processes, mainly landslides and avalanches (snow, rock, clay and debris) pose together with floods the main geohazards in Norway. Landslides and avalanches have caused more than 2000 casualties and considerable damage to infrastructure over the last 150 years. The interdisciplinary research project "GeoExtreme" focuses on investigating the coupling between meteorological factors and landslides and avalanches, extrapolating this into the near future with a changing climate and estimating the socioeconomic implications. The main objective of the project is to predict future geohazard changes in a changing climate. A database consisting of more than 20000 recorded historical events have been coupled with a meteorological database to assess the predictability of landslides and avalanches caused by meteorological conditions. Present day climate and near future climate scenarios are modelled with a global climate model on a stretched grid, focusing on extreme weather events in Norway. The effects of climate change on landslides and avalanche activity are studied in four selected areas covering the most important climatic regions in Norway. The statistical analysis of historical landslide and avalanche events versus weather observations shows strong regional differences in the country. Avalanches show the best correlation with weather events while landslides and rockfalls are less correlated. The new climate modelling approach applying spectral nudging to achieve a regional downscaling for Norway proves to reproduce extreme events of precipitation much better than conventional
\end{abstract}

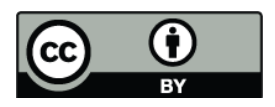

Correspondence to: C. Jaedicke (cj@ngi.no) modelling approaches. Detailed studies of slope stabilities in one of the selected study area show a high sensitivity of slope stability in a changed precipitation regime. The value of elements at risk was estimated in one study area using a GIS based approach that includes an estimation of the values within given present state hazard zones. The ongoing project will apply the future climate scenarios to predict the changes in geohazard levels, as well as an evaluation of the resulting socioeconomic effects on the Norwegian society in the coming 50 years.

\section{Introduction}

The most common geohazards in Norway are related to avalanches, landslides and floods (Gregersen and Sandersen, 1989; Furseth, 2006). Accordingly, in the present paper, the terms "landslide and avalanches" includes snow avalanches, debris flows, rockfalls, rock avalanches and quick-clay slides. Landslides and avalanches are often triggered as a function of distinct meteorological conditions, in particular extreme weather events, such as major storms with heavy rain- and snowfall (Sandersen et al, 1996). Preceded by a complex interaction of meteorological and geological processes acting at short and long time scales, the triggering mechanisms are further complicated by local and regional variations in the snow cover and geology. This makes it difficult to predict deterministically the time and location of any landslide and avalanche event. Short- and long-term meteorological variables such as precipitation, wind and air temperature exhibit a strong control on the timing of landslide and avalanche release and can be used to model the

Published by Copernicus Publications on behalf of the European Geosciences Union. 


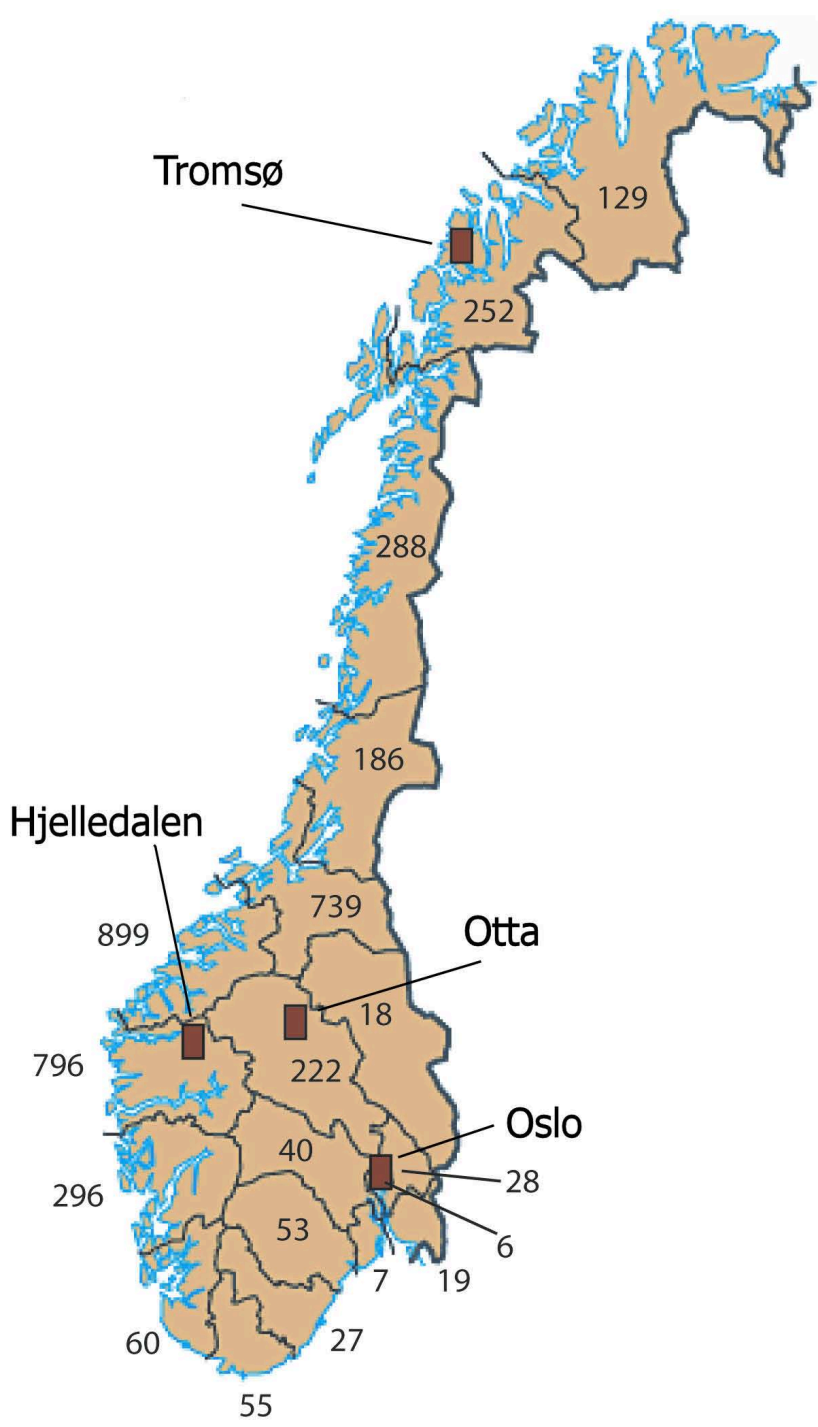

Fig. 1.1 Number of deaths caused by landslides and avalanches in the different Norwegian counties registered in historical archives (1345-1986) (www.skrednett.no, NGU). Brown rectangles show the detailed study areas of this project.

probability of events, given a set of meteorological elements observed in the vicinity of the event. Quick-clay slides in exposed marine sediments represent a particularly high hazard in eastern and central Norway, but do also occur in parts of western and northern Norway. Snow avalanches affect large parts of western and northern Norway and are the geohazard which most frequently leads to loss of lives and infrastructure damage in Norway.

Large rock movements, which can generate devastating tsunamis in the fjords, are most common in western Norway and in the Troms area in northern Norway (Blikra et al., 2006). The number of deaths caused by all types of landslides and avalanches in Norway over the past 150 years exceeds 2000, of which snow avalanches are responsible for
Fatalities related to situation
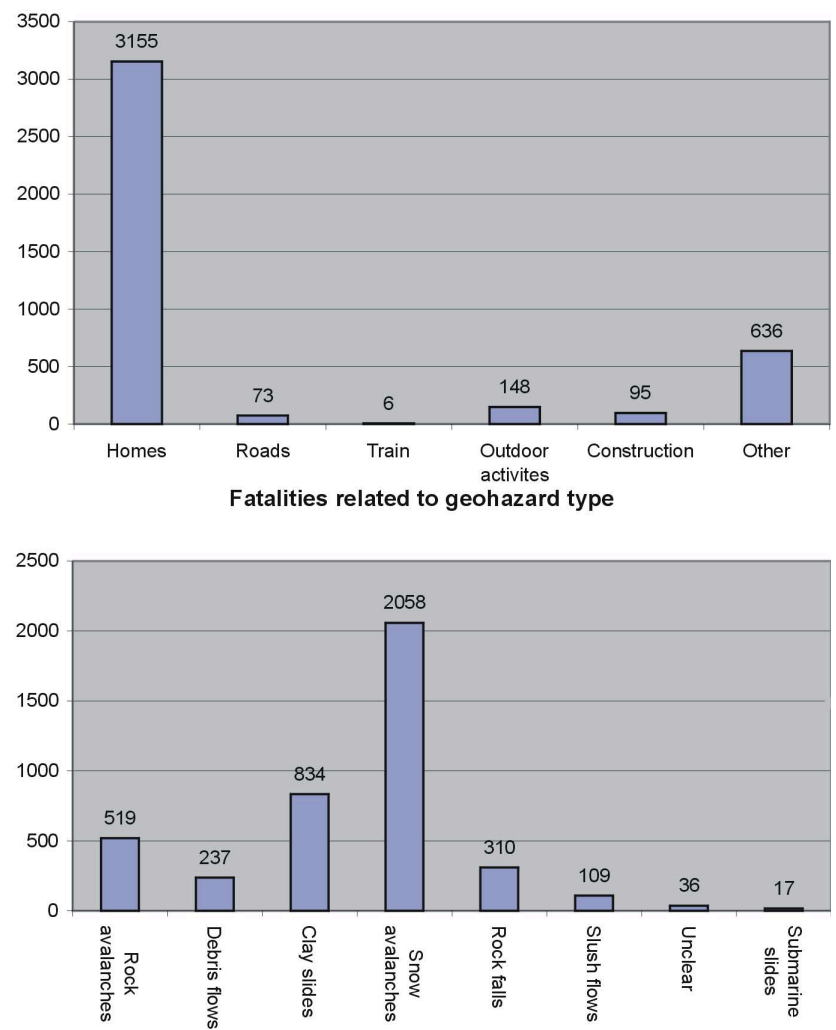

Fig. 1.2. Number of fatalities related to situation and type of geohazard (year 1345-1986) (www.skrednett.no, NGU).

more than 1500 (Fig. 1.1 and 1.2). Due to the widespread development of recreational infrastructure in rural areas, society has become more vulnerable to geohazards, as a consequence of increased use of susceptible areas (NOU 24, 2000).

In addition to a general climatic warming, regional climate models predict increasing frequency and strength of extreme weather events (particularly precipitation) in Norway in the next 50 years (RegClim, 2006). This may lead to an increase in the frequency of situations leading to geohazard events. It should be noted, however, that a climate induced increase in geohazards is not unequivocal. The snow avalanche hazard may for instance, decrease in some regions due to increasing elevation of both the snow line and the tree line and a shortening of the snow season.

Better planning of mitigation measures requires an improved understanding of the relationships between meteorological conditions and geomorphologic processes leading to geohazards, as well as their socio-economic consequences. The GeoExtreme project aims at integrating natural and social sciences with the following main objectives: 
- Establish relationships between meteorological conditions (triggering factors) and geohazards, landslides and avalanches, based on historical records for Norway (1961-2005).

- Produce high-resolution historical (1961-1990) as well as future climatic scenarios for the next 50 years (20002050), as input to assessments of the frequency and magnitude of future geohazard events.

- Establish geohazard scenarios for the next decades in selected regions of Norway based on the historical records and climate scenarios.

- Assess the socio- economic effects of geohazards for the Norwegian society in relation to historical experience (e.g. how society is adapted to cope with geohazards) and future climate scenarios.

This paper gives a presentation of the GeoExtreme project (duration 2005-2008) activities and presents some preliminary results from the ongoing research.

\section{Landslide and avalanche events due to specific mete- orological conditions - Analyses of historical events.}

The objective is to improve the understanding of the coupling between meteorological events and the occurrence of landslides and avalanches by comparing recorded historical events with meteorological data.

\subsection{Materials and methods}

To obtain an overview of historical landslide and avalanche events databases from different authorities and organizations (Norwegian Geological Survey, Norwegian Geotechnical Institute, Road Authorities and others) in Norway were integrated into a database including 20986 landslides and avalanches all over the country. The data covers events where property or life were affected and events without damage. Unfortunately, the spatial and historical coverage of events is limited. Systematic registration of landslide and avalanche events by the road authorities started first in the 1970s, with the majority of registrations in the last 30 years. Earlier events back to the 14th century are limited to destructive events with fatalities or loss of property. For all landslide and avalanche events the spatial distribution is limited to populated areas or transport corridors such as roads and railways. Remote and undeveloped mountain areas are only exceptionally covered by registrations. Details on the database can be found in Jaedicke et al. (2007).

Norwegian meteorological data are available from the first operational observation stations which were established in late 19th century. National datasets covering the entire country are produced for data available after 1961 (Tveito et al., 2005; Jansson et al., 2007). Interpolated daily gridded data

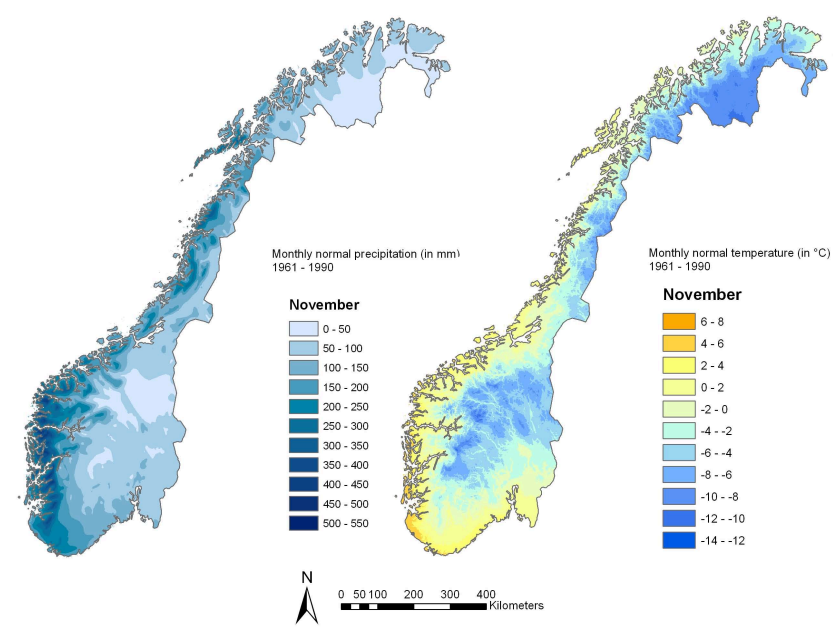

Fig. 2.1 Example of normal (1961-1990) precipitation and temperature grids for the whole of Norway. These $1 \mathrm{~km}$ grids are derived from daily data available from 1961 to present (www.seNorge.no, 2006).

of observed temperature and precipitation has been prepared for the entire country on a $1 \mathrm{~km}$ grid for the period from 1961 until today (Fig. 2.1). This homogenous dataset was used to derive a set of 41 different meteorological elements that could be relevant in releasing landslides and avalanches (e.g. accumulated precipitation over intervals of one to several days, degree days, rain-on-snow events, cold periods, frost cycles, etc.) by simple matrix calculations on the entire grids (Vikhamar-Schuler and Isaksen, 2006). Additionally, results from reanalysis data of sea pressure (Uppala et al., 2004) were used to produce daily wind fields for the same period.

For each landslide and avalanche event that had a known date and location within the period 1961 to 2005 (a total number of 20000 events out of the total 20 986) the 41 meteorological elements were extracted from the meteorological grids. This data set was then used in a classification tree analysis to identify the most relevant meteorological elements causing landslides and avalanches.

\subsection{Results}

The results show that snow avalanches have the highest correlation with meteorological elements such as wind and precipitation while rockfalls show the lowest correlation. The most important elements triggering landslides or avalanches vary spatially over the country. While precipitation is the most important trigger for snow avalanches in the coastal western part of the country, wind plays an important role in northern Norway (Fig. 2.2). Debris flows can be explained both by short-term intensive precipitation events as well as rain accumulating over a longer period of up to 15 days. Most likely this can be explained with two different geomechanical 


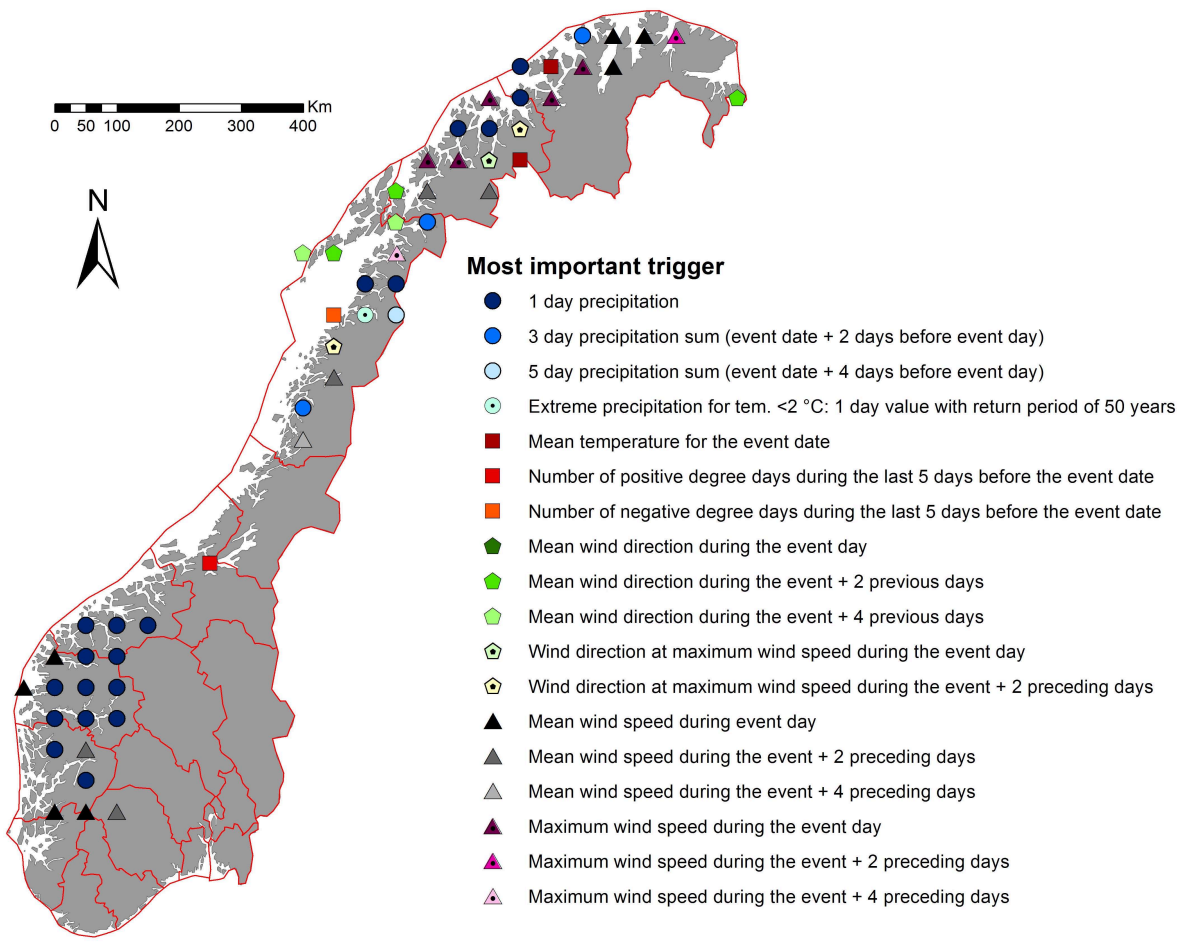

Fig. 2.2 Most important trigger for snow avalanche release. Each symbol represents the clustered results from a $50 \mathrm{~km}$ square. The cluster is chosen to obtain a minimum number of events to secure statistical significance. Areas without symbol show too few observations or results without statistical significance.

release processes: a) surface erosion during short and intense storm events and b) slow build up of soil pore pressure over longer time periods with lower rainfall intensity. In addition, snowmelt in spring is an important triggering factor for debris flows in Norway.

The inhomogeneous data acquisition for the landslide and avalanche database prohibits a frequency analysis directly on the recorded events. Therefore, the combination of meteorological data from a homogenous dataset with the landslide and avalanche database bypasses these limitations. Frequency analysis on the most important trigger elements will allow comparison with future climate scenarios.

\section{Regional modelling of current climate and future cli- mate scenario}

The objectives are to produce high resolution climate and weather scenarios for the present and the next 50 years with special focus on extreme events.

\subsection{Materials and methods}

\subsubsection{Modelling of historic to current regional climate}

The reanalysis from National Centres for Environmental Prediction (NCEP) and the European Centre for Medium Range
Forecasts (ECMWF) are together with point observations the best estimate of the historic state of the atmosphere. However, to some extent, it deviates from the true, unknown state. The large scales are best described, simply because they are better sampled by the observational network and the resolution of the data assimilation systems. Local climate details on scales of $100 \mathrm{~km}$ or less are insufficiently represented and subject to significant uncertainty. As the reanalysis only provides the large scale features, regionally higher resolved models may be used to dynamically downscale information from the atmosphere. To date, in nearly all dynamical downscaling studies performed, the forcing is administered exclusively at the lateral boundaries of the area in focus. The problem resulting from only imposing the large scale forcing on the boundaries has become more apparent as experiences with regional climate models have grown during the last decade (Vukicevic and Errico, 1990, Jones et al., 1995, Miguez-Macho et al., 2004). To reduce these problems selective spectral nudging (Waldron et al., 1996) in a global climate model (Arpege/IFS; Deque et al., 1994; Deque and Piedelievre, 1995; Deque et al., 1998) with a stretched grid configuration is proposed. The nudging provides large scale flow consistent with the large scale circulation obtained from the reanalysis, but let the model freely develop small-scale features related to topography and local scale circulation patterns (von Storch et al., 2000, 2004). 
Using the selective spectral nudging in a global model will also eliminate the problem related to the technical treatment of the lateral boundaries. This is a novel approach, which may be of importance in modelling of extreme events as it ensures that variability on all the nudged scales are maintained in the system. The results will provide a valuable dataset for analyzing and understanding local extreme events which are poorly represented by the coarse resolution reanalysis and the observational network, and make it possible to link this to investigate past geohazard events. Figure 3.1 shows the stretched grid of the applied model with the focus point of highest resolution in the North Sea.

The Arpege/IFS system is well suited for doing the spectral nudging since it shares the same dynamical core and vertical coordinate system as the ERA40 reanalysis (Uppala et al., 2004). To reduce errors related to vertical interpolations, the model is run with the same vertical levels as the ERA40 (60 levels). The reanalysis is available in spectral space on its original resolution every $6 \mathrm{~h}$, and are linearly interpolated to the stretched grid configuration and to model time steps so that the data can be nudged into the system at every time step. Technical details can be found in Barstad et al. (2006).

The dataset will contain high resolution physical consistent data of winds, cloud cover, precipitation, temperatures, soil temperatures and moisture, snow cover, snow water equivalent etc. every 3 to $6 \mathrm{~h}$ from 1961 to 1990 . The uncertainty in the different variables will be dependent on the quality of the large scale features in the ERA40 data and on how constrained the variable is by the observed quantities that go into the ERA40 reanalysis. Thus, variables induced by local factors (for example local convective precipitation, sea breeze etc.) are more uncertain than variables that are constrained by the large scale flow (for example frontal precipitation, winds related to large scale cyclones etc.)

\subsubsection{Modelling of future climate}

The same model configuration without the nudging is run using prescribed Sea Surface Temperature (SST) changes from a global coupled climate model. Two 30-year simulations corresponding to 1961-1990 and 2036-2065 are performed. Monthly mean observed SST is used for the present climate simulation (1961-1990). This allows for the validation of the variable resolution model by comparing the simulation with observations. Another advantage is that SST forcings from different models can be tested without running different control simulations, allowing more experiments due to saved computer time. From 2035 through 2065, monthly SSTs are created by adding anomalies from the described coupled scenario to observed SSTs. By using only anomalies any SST biases in the coupled model will be removed.
Table 3.1 The models nudged simulation $(\operatorname{arpN})$ and ERA40 reanalysis (e4) versus observation error in \% for different percentiles. All Norwegian precipitation and coastal wind stations considered. Negative sign indicates underestimation by the models at given percentile.

\begin{tabular}{lllrr}
\hline \multirow{2}{*}{ Percentile (\%) } & \multicolumn{2}{c}{ Daily precipitation } & \multicolumn{2}{c}{ Daily wind } \\
\cline { 2 - 5 } & e4 & arpN & e4 & arpN \\
\hline 50 & -53.14 & -11.58 & 29.60 & 35.13 \\
90 & -41.94 & -18.43 & -2.39 & 4.49 \\
95 & -45.31 & -20.32 & -8.31 & -0.78 \\
99 & -51.36 & -24.63 & -17.62 & -8.62 \\
\hline
\end{tabular}

\subsection{Results}

Here results from the nudge downscaling are shown for comparison with observations in the time period 1961-1990. Generally, the nudged simulation shows good agreement for wind, temperature and precipitation. In reference to the original ERA40 dataset, the largest improvements are found for winds along the coast and for precipitation. Fig. 3.2 presents examples of wind and precipitation distribution for some stations along the coast. Generally, days with wind up to $15 \mathrm{~m} / \mathrm{s}$ are slightly overestimated. More windy days are slightly underestimated. Maximum winds are considerably higher than in ERA40 and more in line with the observations. Table 3.1 shows percentiles for model comparison for all precipitation and coastal wind stations in Norway. The table indicates similar tendency as Fig. 3.2. Comparison of daily precipitation shows a clear improvement in the nudged simulation compared to the ERA40 dataset, both for small and high daily accumulation sums. For the 99 percentile, the nudged simulation has about $25 \%$ underestimation while the ERA 40 has about $50 \%$, see Table 3.1. The temperature in the nudged simulation verifies well, but in cold winter days $\left(<-10^{\circ} \mathrm{C}\right)$ at inland stations, the nudged simulation (and ERA40) appears somewhat too warm (not shown) possibly related to problems in simulating the strength of shallow inversion layers. In general the nudged simulation gives added value in both the mean and extreme cases compared to the ERA40.

The results form the future climate scenarios will be available in mid 2008 and provide the basis for the analysis of future changes in the landslide and avalanche pattern in Norway.

\section{Future changes in geohazard patterns based on cli- mate model scenarios}

The objective is to use the results from the historical analysis of slope events in combination with the future climate scenarios to establish future hazard scenarios in selected regions of Norway. 


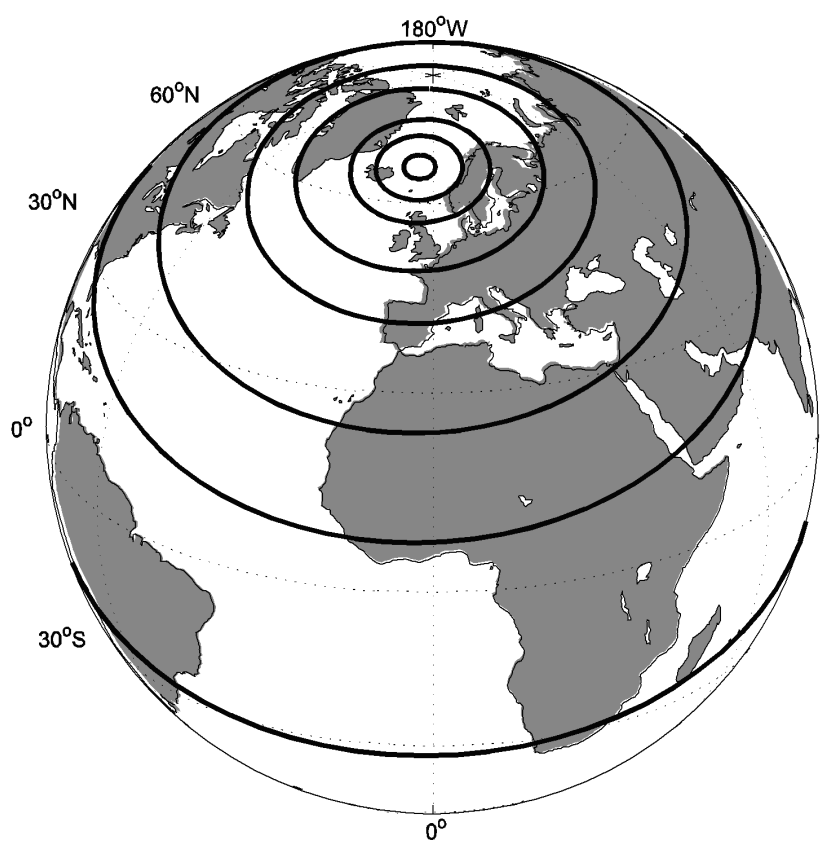

Fig. 3.1 Horizontal coordinate geometry for the stretched model. Isolines indicate 25, 30, 35, 40, 50, 70, 90 and $100 \mathrm{~km}$ grid distance with focus point in the North Sea, just off shore from Norway.

\subsection{Materials and methods}

Changes in the climatic regime cause basically a change in the trigger level for landslides and avalanches and thereby change the frequencies and location of such events. Accordingly, a new geohazard pattern may influence the vulnerability of threatened objects and infrastructure.

The study is concentrated on four key areas (Fig. 1.1) that are different with respect to dominating landslide and avalanche types, climate, and the population and infrastructure pattern. The four areas are:

1. The Oslo area, Southeast Norway at $60^{\circ} \mathrm{N}, 60 \mathrm{~km}^{2}$. The Oslo area is the most heavily populated area in Norway with almost $1 / 3$ of the total population including the capital. Focus is on landslides in marine clays. The area is known for its unstable ground and quickclay landslide accidents (e.g. Furseth, 2006) occur frequently in connection with events of long-lasting or intensive precipitation and high river discharge (Jaedicke and Kleven, 2007).

2. The Troms $\varnothing$ area, North Norway at $69^{\circ} \mathrm{N}, 30 \mathrm{~km}^{2}$. Due to the alpine fjord landscape relatively large areas of the town of Troms $\emptyset$ are situated in hazardous areas, threatened by snow avalanches, debris flows and rockfalls. The suburban areas are growing extensively, and the pressure on land for construction purposes is pushing the limits into hazardous areas in the mountain sides.
3. The Hjelledalen valley, West Norway at $62^{\circ} \mathrm{N}, 30 \mathrm{~km}^{2}$. This is a narrow glacially shaped valley with $1000 \mathrm{~m}$ high mountains on each side. The valley is affected by snow avalanches, rockfalls and debris flows. It is scarcely populated but contains one of the main roads connecting eastern and western Norway. The study in this area mainly focuses on snow avalanches but also rockfalls and debris flows are studied.

4. The Otta area, Gudbrandsdalen valley, East Norway at $62^{\circ} \mathrm{N}, 25 \mathrm{~km}^{2}$. The Otta area is one of the driest areas in Norway with only $375 \mathrm{~mm}$ annual precipitation (www.met.no). Nevertheless, the area is also known for its floods and accompanying shallow landslides and debris flows. Existing debris flow data (Sletten, 2002; Sletten and Blikra, 2007) show a probability of about 1 event each 500-1000 years in most of the flow tracks. An important task is to evaluate the probability of a new major event, equivalent to the devastating landslides during the "Storofsen" flood in 1789, in a future climate regime.

In order to quantify changes in landslide and avalanche hazard, the initial step was to describe the present situation in the four study sites. By the use of hazard zonation detailed hazard maps with regard to different return periods and type of events were established. The hazard zonations are based on input from mapping of colluvium, slide tracks and source areas (Fig. 4.1), modeling of susceptibility for shallow landslides (Fig. 4.2) and modelling of potential avalanche and rockfall run-out distances. Using the results from the statistical analysis of landslide and avalanche versus weather events and the downscaled climate modelling, the established hazard maps for the present climate will be modified to represent an estimate around year 2050. The results of the case studies will be used for a regional extrapolation of the effects of future climate scenarios on geohazard problems.

4.2 Example: modelling of shallow landslide probability at present precipitation conditions and future scenario

In this section the selected modelling approach to study the effect of changes in precipitation on shallow landslide initiation in the Otta area will be presented. Some preliminary results are shown as well.

\subsubsection{Methodology}

The main idea of this part of the project is to analyse the stability conditions for shallow landslides considering present and future precipitation scenarios, by coupling a hydrological model with infinite slope stability analysis. In order to evaluate a large set of precipitation conditions, and thus modelling the response of soil to short and long term precipitation events, 3 hydrological modelling approaches have been 

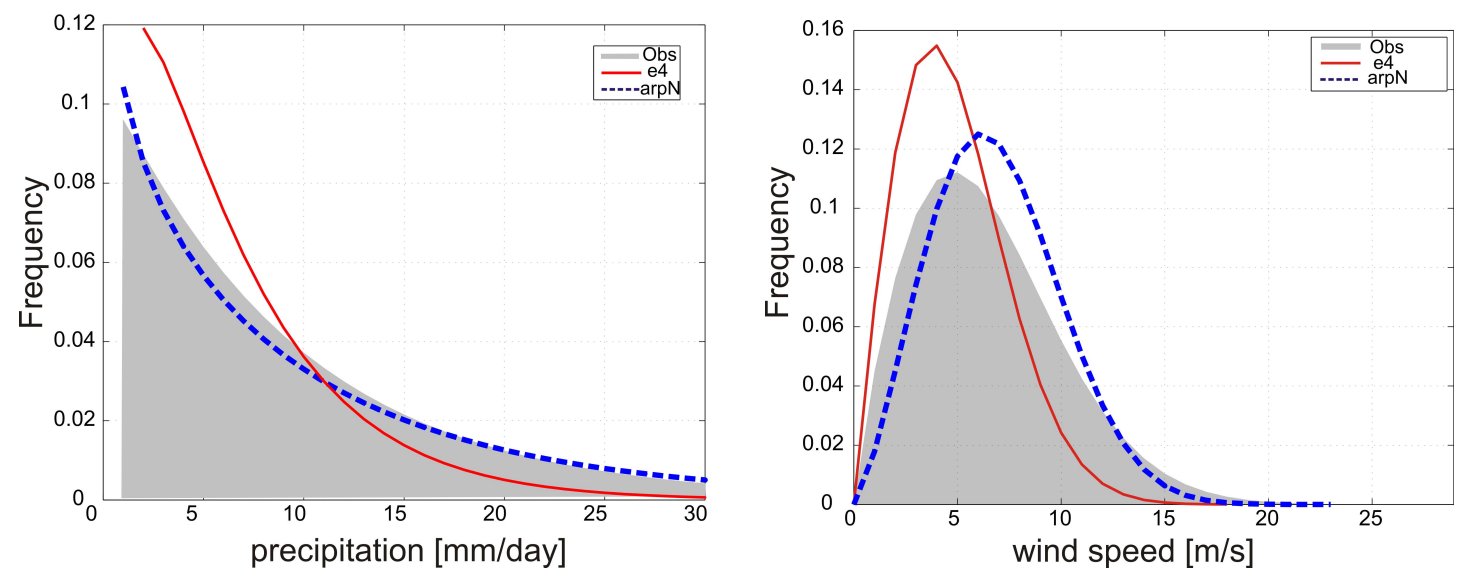

Fig. 3.2 For the evaluation period (1961-1990), (a) Daily precipitation distribution for 5 stations (Suldalsvatn, Gullbrå, Ørskog, Namdalseid, Lurøy), (b) Daily wind distribution for 5 coastal stations (Hellisøy, Obrestad, Oksøy, Lindesnes, Lyngør). Solid red lines are ERA40 (e4) and broken blue lines are the nudge downscaled results $(\operatorname{arpN})$. Observations are indicated in shading.

tested: steady subsurface flow model (Montgomery and Dietrich, 1994), diffusivity transient model (Iverson, 2000), and a combination of them (D'Odorico et al., 2003; D'Odorico et al., 2005). Taking into consideration the uncertainty of the data and the difficulty to calibrate the model with actual events, Monte Carlo simulations were used.

The spatial variability of soil parameters was modelled by using the Quaternary map (Fig. 4.1). This map contains information about type and thickness of deposits.

The deposits are classified as discontinuous when the soil thickness is less than $1 \mathrm{~m}$ and continuous when the thickness is larger than $1 \mathrm{~m}$. Locally, the continuous deposits can reach up to 3-4 m of thickness. To each deposit a set of soil properties was assigned according to the following criteria:

- Hydraulic conductivity was estimated from grain-size distribution analysis, carried out on sediment samples collected in close proximity of landslide scars in the Otta area.

- Cohesion, friction angle, and soil unit weight were derived from laboratory analysis of the deposits sampled in the field.

Regarding the precipitation, it was decided to focus on extreme events with 5, 100, and 1000 years return period and duration of 1 day. The analysis of extreme precipitation (Alexandersson et al., 2001) has shown that the selected return periods correspond to precipitations of 39,69 , and $105 \mathrm{~mm} / \mathrm{d}$ respectively. Since, at the moment, no future climate simulations were available, a $20 \%$ increase of precipitation was assumed according to the scenarios of extreme events modelled for the period 2030-2049 (Skaugen et al., 2002).

For each selected precipitation the peak pressure head is calculated thus allowing the evaluation of the Factor of Safety (FS) at the critical time for each event. This procedure was repeated for each of the Monte Carlo simulation

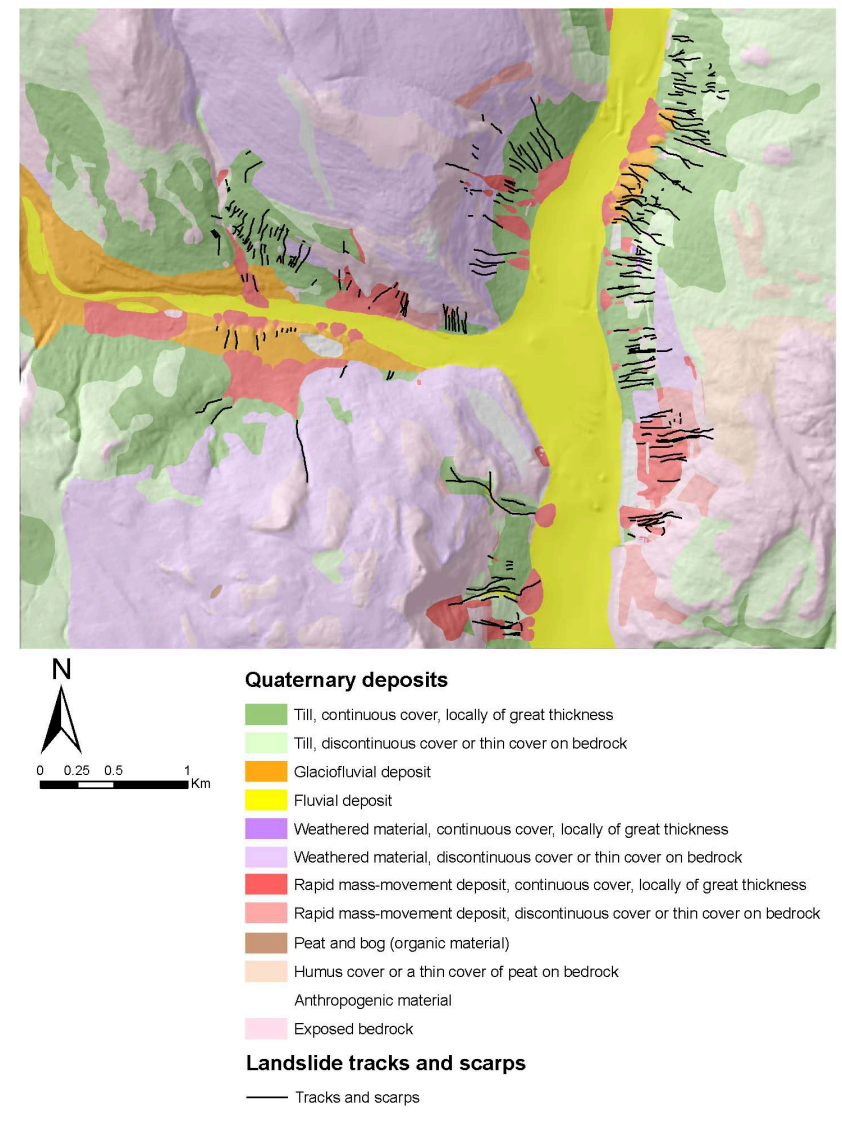

Fig. 4.1 Map of Quaternary deposits of the Otta area.

(5000 in total) and the probability of failure (i.e., the probability of FS $\leq 1$ ) was calculated.

\subsubsection{Results}

In Fig. 4.2 (a) one result of the stability analysis is shown. In this case the piezometric conditions were modelled by using a combination of subsurface flow model and diffusivity 


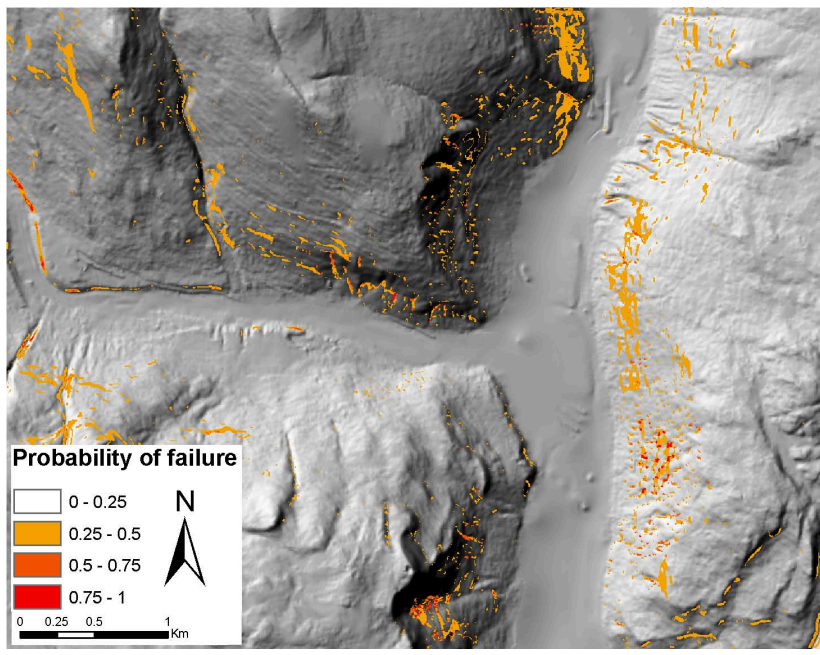

Fig. 4.2a Modelling of the present stability conditions for shallow land slides. The probability of failure is calculated for $69 \mathrm{~mm} / \mathrm{d}$ precipitation with a return period of 100 years.

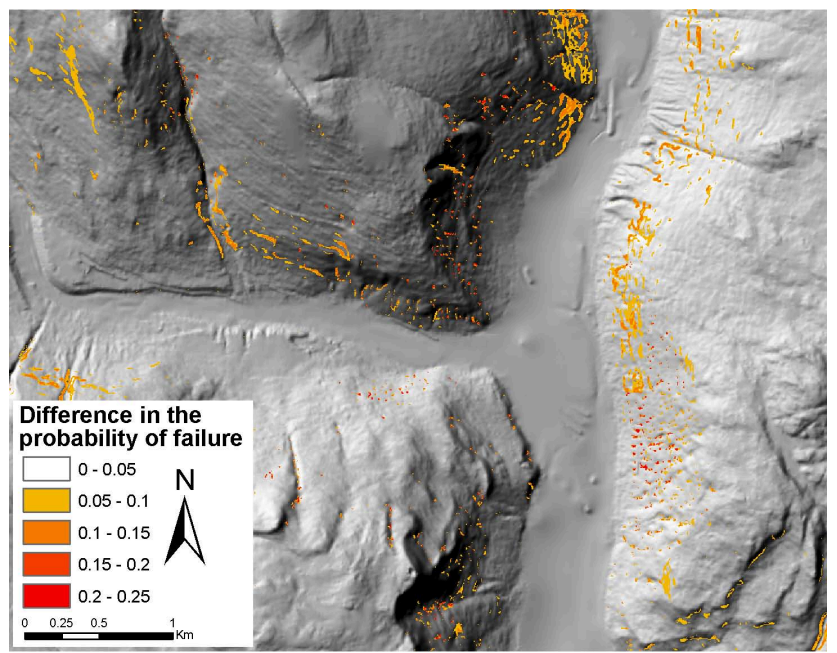

Fig. 4.2b An increase of $20 \%$ in the precipitation intensity is assumed. The results are visualized as the difference between the probability of failure at the present precipitation conditions (Fig. 4.2a) and the probability of failure at the modelled future conditions. Areas showing decreased probability of failure were not detected in the study area.

transient model. The precipitation was set at $69 \mathrm{~mm}$ per 1 day corresponding to a 100 year return period. Assuming an increase of $20 \%$ in rainfall (i.e., $83 \mathrm{~mm} / \mathrm{d}$ ), the same hydrological model was run to understand the influence of changes in precipitation on the stability conditions. The comparison between present condition and future scenario is shown in Fig. 4.2 (b) as difference in probability of failure. The analysis of the simulations has shown that for some potential source areas the difference in the probability of failure between present conditions and future scenario is statistically significant.

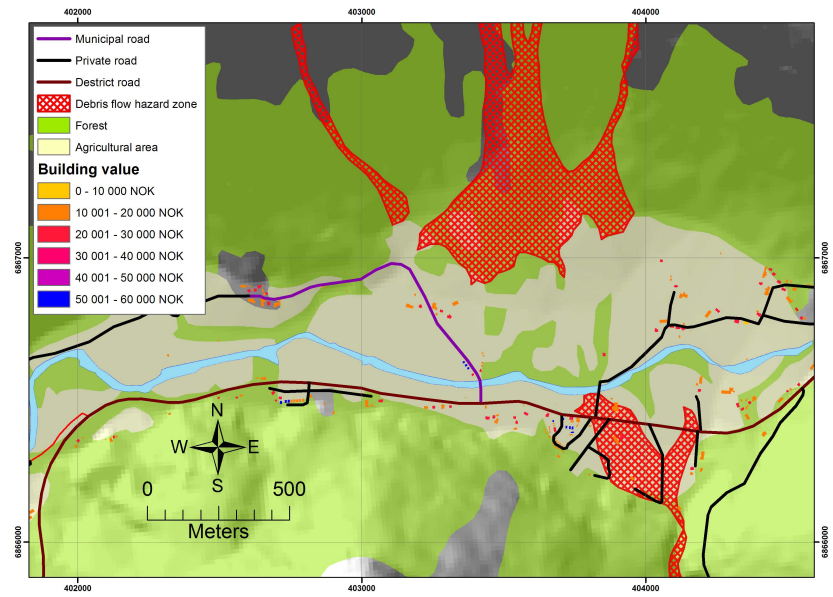

Fig. 5.1 Map of Hjelledalen showing the estimated value of buildings and extent of debris flow hazard zones annual probability $1 / 100(1 € \approx 8 \mathrm{NOK})$.

The present analysis (Fig. 4.2a and b) is based on a $50 \mathrm{~km}$ meteorological grid model. Higher precision in the results is expected once the high resolution climate modelling is available. A similar modelling strategy may also be used in the Tromsø area.

\section{Socio-economic consequences of future changes in geohazards}

The objective of the socio-economic analysis is to estimate the cost of a change in the frequencies of geohazard events in a future climate. Two challenges will be addressed in particular. First, the geographical dimension in which the hazard zones for landslides and avalanches are given is not straightforwardly dealt with by standard economic analytical tools. Second, the damage of an event with a given return period depends on how well people at risk are prepared. Thus, the increase in damage related to climate change is also subject to precautionary actions taken to prevent or protect against damage.

When the risk is known, criteria for adaptation are developed by calculating the expected loss from landslides and avalanches. There are many examples of people that adapt inadequately to known risks of natural hazards, and risk management in cases of natural hazards is poorly understood (Pollak, 1998). Several explanations have been provided, but this study addresses the fact that individuals do not carry the full responsibility of natural hazard risks in Norway. It shows also how the cost of landslides and avalanches is likely to exceed the cost of cost-effective adaptation. Cost-effective adaptation is defined as the expected social cost of landslides and avalanches when actors purchase insurance in a perfect insurance market. 
Table 5.1 Value of capital objects at risk of landslides and avalanches in Hjelledalen. Mill. NOK*

\begin{tabular}{lrrrr}
\hline & \multicolumn{2}{c}{ Avalanches } & Debris flows & Rockfalls \\
\cline { 2 - 5 } & $\begin{array}{r}\text { 100 years } \\
\text { proba. }\end{array}$ & $\begin{array}{r}1000 \text { years } \\
\text { proba. }\end{array}$ & $\begin{array}{r}\text { 100 years } \\
\text { proba. }\end{array}$ & $\begin{array}{r}100 \text { years } \\
\text { proba. }\end{array}$ \\
\hline Buildings & 114.3 & 183.9 & 102.8 & 300.6 \\
Roads & 0.0 & 0.0 & 0.0 & 497.0 \\
Land & 7.7 & 52.5 & 4.4 & 54.1 \\
\hline
\end{tabular}

$* 1 € \approx 8 \mathrm{NOK}$

\subsection{Mapping the elements at risk}

The damage estimates are based on a mapping of the elements at risk in the area. This is derived by combining maps over assets and maps over areas with landslide and avalanches of different return periods. Both are provided as digital maps. GIS information about existing real capital was applied. High resolution GIS-data scale 1:5000 allowed us to limit the grids in Hjelledalen to $1 \times 1 \mathrm{~m}$ (Fig. 5.1). The map indicates buildings, roads, forested land and agricultural zones. Neither damage on mobile objects, nor damages to humans are included in the estimates. Each grid point is covered by one and only one object. Thus, the value of the grid can be attached according to the observed object, which is classified as land, certain types of buildings or local, regional and national standards of roads. If only less detailed information is available, the valuation of objects will be less specific, but the same approach is applied.

To estimate the damage from landslides and avalanches, the elements at risk map was coupled with probability maps indicating zones subject to landslides and avalanches. The landslides and avalanches were divided into three categories (snow avalanches, rockfall, debris flows), and the probability of snow avalanches were given for both one event per 100 and 1000 years. The hatched areas (red) in Fig. 5.1 indicate the extension of debris flows of a 100 years return period.

The maps constitute the information required to make an inventory of values at risk in the area, which are shown in Table 5.1. The detailed information allows for a specification of capital category. Buildings represent the largest capital category at risk in this area for most events. Roads with a relatively large value are, however, found in areas with a risk of rockfalls.

\subsection{Evaluation of development in hazardous areas}

Under the assumption, that an event destroys everything within the hazard zone (e.g. the vulnerability is set to 1 ), the expected damage is found by multiplying the value of the elements at risk and probabilities of occurrence of geohazards $(0.01$ for events with 100 year's frequency, and 0.001 for events with 1000 year's frequency). However, events rarely damage the entire value of the object in place. The damage

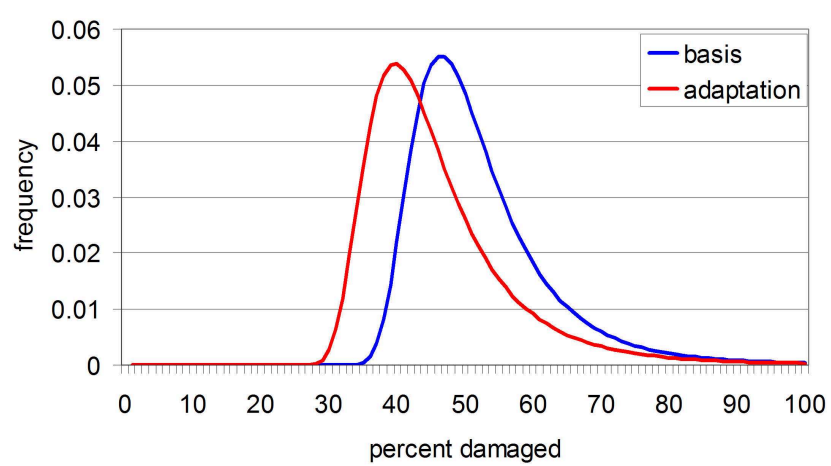

Fig. 5.2 Examples of damage frequencies to buildings of snow avalanches and debris flows occurring with a probability of 0.01 . Expected damage frequency for current state (basis) of the buildings and for improved design (adaptation) to prevent damages from debris flows and avalanches.

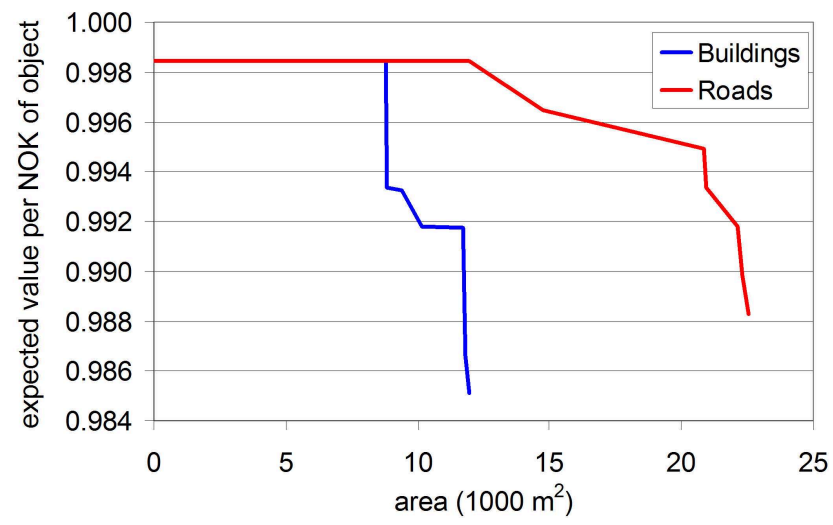

Fig. 5.3 Illustration of a ranking of grids according to event probabilities using buildings and roads in Hjelledalen.

extent will most likely depend on the type of object and the type of landslide or avalanche.

To take the differences of such characteristics into account, an exponential distribution of the form $F(z)=\exp \left(-\beta z^{\alpha}\right)$ was assumed as a damage function for each type of event and for each category of capital. $z$ is a stochastic variable, which represents a range of variables, partly related to the nature of the event, such as the force of an event, and partly to the object that is hit. With the detailed information about objects at risk in this study, the main stochastic element is likely to be related to the nature of the event. With larger grids however, a main element will be related also to what kind of values are at risk at the spot. The function $F(z)$ measure the share of damage if the stochastic variable takes the value $z$.

In the example (Fig. 5.2), the typical damage of a 1000 year avalanche is about 50 percent of the value in place, which is shown by the blue distribution. The red distribution illustrates a possible effect of implementing a measure to prevent or protect against damage, which in this case gives 

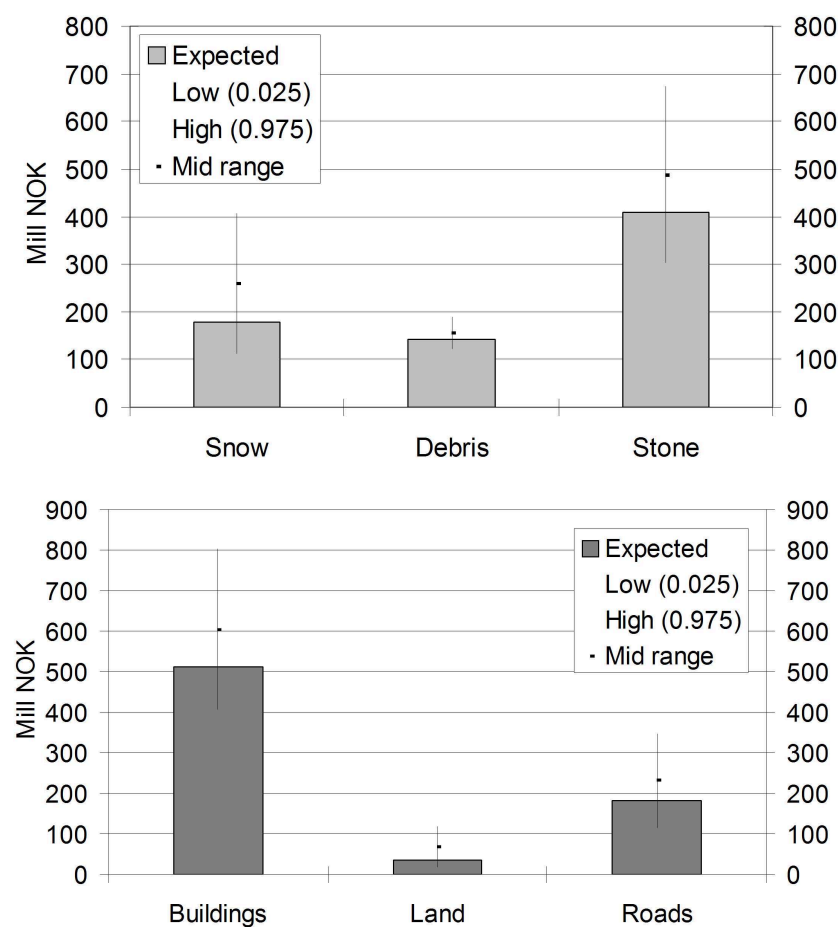

Fig. 5.4 Expected, high and low annual cost by type of events and by category of capital in Hjelledalen. ( $1 € \approx 8 \mathrm{NOK})$.

a slight reduction in the expected damage. A question being raised in this project is under what conditions such measures will be implemented.

The distributions in Fig. 5.2 allow ranking the area according to risk. A useful measure for ranking is the certainty equivalent value of one Norwegian krone in place. For a risk neutral agent, this is one minus the expected damage of an event, that is, similar to a ranking according to the probability of landslides or avalanches. The ranking is shown in Fig. 5.3 for buildings and roads in the example from Hjelledalen. With a given standard for the level of security with respect to landslides and avalanches, the excess $\mathrm{m}^{2}$ development that has taken place under some criteria for acceptable risk set by the central authorities can be estimated. The excess development can be read as the difference between the area at end point of each curve and the intersection between the curve and a safety standard on the $y$-axis in Fig. 5.3. For example, if central authorities set a limit of 0.995 as the lowest permitted probability, the excess development indicated by Fig. 5.3 is approximately $3000 \mathrm{~m}^{2}$ for buildings and $2000 \mathrm{~m}^{2}$ for roads.

Because of the excess development, the social cost of landslides and avalanches also becomes higher than they would be if the safety standard was followed. An illustration of the expected present-day cost of landslides and avalanches in the Hjelledalen area is shown is Fig. 5.4. The numbers are, based on very vague approximations of damage functions, and should not be taken as absolute, but are given as examples of information that will be provided by the project.
Note also that the figures include economic costs only. No attempts were made to estimate the risk of life and injuries. As for the impacts of climate change, excess damage at present suggests that also an increase in the frequency of events will give an excess increase of damage. Better and more research based estimates of the damage distributions illustrated in Figure 5.2 will be developed in the project, and hazard zones as well as damage estimates will be made also for scenarios for future climate change.

For policy making, it is important to know what to do in order to attain a management regime that minimizes the extra costs that is related to the regime. This will also be subject to analysis in the remainder of the project. Focus will be in particular on what incentives central authorities may implement in order to make local authorities restrict permissions and thereby obtain development of areas that better corresponds to central authorities' safety standards.

\section{Conclusions}

The aim of the GeoExtreme project is to study the changing geohazard pattern in Norway due to a changing climate. A major focus in the project is to consider national datasets and use the study areas as verification rather then the other way round. Contrary to conventional research approach, to go into detail, the national picture was in focus. This objective was formulated out of the request from decision makers and politicians to present results that can serve as a basis for national priorities in climate change adaptation. This approach prohibited detailed process studies in selected areas, selected slopes or on single rocks. The results from GeoExtreme give a general overview over the whole of Norway. The study showed that the limitations of inhomogeneous data collection of landslide and avalanche events can be bypassed by combining the event database with a homogeneous meteorological dataset. This allows then statistical analysis to find the most important meteorological trigger elements for the various types of landslides and avalanches. The identified most important triggering element for different types of landslides and avalanches show a wide spatial variation on national scale in Norway. This implies that adaptation strategies need to consider regional differences already on the national planning level.

For future scenarios these regional differences can only be addressed with more detailed climate modelling. The new climate modelling approaches on a stretched grid successfully model extreme value frequencies on scales that correspond to the results from the statistical analysis of the slide events.

More detailed investigations of study areas and slope stability modelling give an impression of the consequences of a changing climate geohazard level for communities and settlements in the future. Again, regional differences will ask for adjustments of national climate adaptation strategies to 
the local conditions. The socio economic analysis shows that future geohazard risks may be limited by an unambiguous connection of the local authorities' right to decide and approve new development and their responsibility for damages by geohazards.

As a consequence, it is recommended to consider possible future changes to the geohazard level already in the planning phase of any new development and to adjust these considerations to the local and regional differences in the expected changes.

Edited by: M. Keiler, S. Fuchs and T. Glade

Reviewed by: two anonymous referees

\section{References}

Alexandersson, H., Førland, W. J., Helminen, J., Sjöblom, K., Tveito, O. E.: Extreme value analysis in the Nordic countries, Norwegian Meteorological Institute, Olso, Norway. Report 13/01 Klima, p. 19, 2001.

Barstad, I., Sorteberg, A., and Flatøy, F.: Spectral nudging using a streched version of ARPEGE/IFS, Technical description, in: The "GeoExtreme" Project Geohazards, climate change and extreme weather events, Status Report 2006, online available on: www. uib.no/People/gbsag/publications.html, 2006.

Blikra, L. H., Longva, O., Braathen, A., Anda, E., Dehls, J., and Stalsberg, K.: Rock slope failures in Norwegian fjord areas: Examples, spatial distribution and temporal pattern, in: Landslides from massive rock slope failures, edited by: Evans, S. G., Mugnozzza, G. S., Strom, A., et al., NATO Science Series, Springer, 475-496, 2006.

Deque, M., Dreveton, C., Braun, A., and Cariolle, D.: The Arpege/Ifs Atmosphere Model - A Contribution To The French Community Climate Modeling, Clim. Dynam., 10, 249-266, 1994.

Deque, M., Marquet, P., and Jones, R. G.: Simulation of climate change over Europe using a global variable resolution general circulation model, Clim. Dynam., 14, 173-189, 1998.

Deque M. and Piedelievre, J. P.: High-Resolution Climate Simulation Over Europe, Clim. Dynam., 11, 321-339, 1995.

D'Odorico, P. and Fagherazzi, S.: A probabilistic model of rainfalltriggered shallow landslides in hollow: a long-term analysis, Wat. Res. Res., 39(9), p. 1262, doi:10.1029/2002WR001595, 2003.

D’Odorico, P., Fagherazzi, S., and Rigon, R.: Potential for landsliding: dependence on hyetograph characteristics, J. Geophys. Res., 110, F01007, doi:10.1029/2004JF000127, 2005.

Furseth, A.: Slide accidents in Norway (in Norwegian), Tun Forlag, Oslo, 207 pp., 2006.

Gregersen, O. F., and Sandersen, F.: Landslide: Extent and economic significance in Norway, in: Proceedings of the 28th Int. Geo. Congress: Symp. on Landslides, 133-139, 1989.

Iverson, R. M.: Landslide triggering by rain infiltration. Wat. Res. Research, 36, 1897-1910, 2000.

Jaedicke, C. and Kleven, A.: Long term precipitation and slide activity in south-eastern Norway, autumn 2000, Hydrol. Proc., 22(4), 495-505, 2007.
1

Jansson, A., Tveito, O. E., Pirinen, P., and Scharling, M.: NORDGRID: A preliminary investigation on the potential for creation of a joint Nordic gridded climate dataset, met.no report no. 03/2007, Climate, p. 48, 2007.

Jones, R. G., Murphy, J. M., and Noguer, M.: Simulation of climate change over Europe using a nested regional-climate model, in: Assessment of control climate, including sensitivity to location of lateral boundaries, Q. J. Roy. Meteorol. Soc., 121, 1413-1449, 1995.

Miguez-Macho, G., Stenchikov, G. L., and Robock, A.: Spectral nudging to eliminate the effects of domain position and geometry in regional climate model simulations, J. Geophys. Res., 109, D13104, doi:10.1029/2003JD004495, 2004.

Montgomery, D. R. and Dietrich, W. E.: A physically based model for the topographic control on shallow landsliding, Wat. Res. Research, 30, 1153-1171, 1994.

Norwegian public review (NOU 24): A vulnerable society (Et sårbart samfunn), Norwegian Ministery of Justice and the police, in Norwegian, ISBN: 82-583-0537-9, 352 pp., 2000.

Pollak, R. A.: Imagined risks and cost-benefit analysis, The American Economic Review, 88(2), 376-380, 1998.

RegClim (Regional Climate Development Under Global Warming): A Multi-institutional Norwegian Project sponsored by the Norwegian Research Council (online available on: www.nilu.no/ regclim), 2006.

Sandersen, F., Bakkehøi, S., Hestnes, E., and Lied, K.: The influence of meteorological factors on the initiation of debris flows, rockfalls, rockslides and rock mass stability, in: Landslides, Proceedings of the 7th symposium on landslides, edited by: Senneset, K., Trondheim, 17-21 June 1996, 97-114,1996.

Senorge.no, http://senorge.no/startpage.aspx, as 11 March 2008.

Skaugen, T., Astrup, M., Roald, L. A., and Skaugen, T. E.: Scenarios of extreme precipitation of duration 1 and 5 days for Norway caused by climate change, NVE-report A 7/02, 2002.

Sletten, K.: Holocene mass-movement processes in Norway, and the development of a moraine complex on Svalbard. Geomorphology, sedimentology, chronostratigraphy and palaeoclimate, Dr. scient. thesis, Department of Geology, University of Bergen, 284 pp., 2002.

Sletten, K. and Blikra, L. H.: Holocene colluvial (debris-flow and water-flow) processes in eastern Norway: stratigraphy, chronology and palaeoenvironmental implications, J. Quat. Sci., 22, 619-635, 2007.

Tveito, O. E., Bjørdal, I., Skjelvåg, A. O., and Aune, B.: A GIS based agro-exologicaldecision system based on gridded climatology, Meteor. Appl., 12(1), 57-68, 2005.

Uppala, S., Kållberg, P., Hernandez, A., and 7 others: ERA-40: EQMWF 45-years reanalysis of the global atmosphere and surface condition 1957-2002, ECMWF Newsletter No. 101, online available on: http://www.ecmwf.int/publications, 2004.

Waldron, K. M., Peagle, J., and Horel, J. D.: Sensitivity of a spectrally filtered and nudged limited area model to outer model options, Mon. Weather Rev., 124, 529-547, 1996.

1

Jaedicke, C., Lied, K., Juvet, H., and Kronholm, K.: Integrated Database for Rapid Mass Movements in Norway, submitted to Landslides, 2007. 
Vikhamar-Schuler D. and Isaksen, K.: Extracting climate variables for statistical analysis of climate and geohazards, GeoExtreme technical report, 1, 9-15, 2006.

von Storch, H. and Feser, F.: Spectral nudging in regional climate modelling: Does it induce additional gravity waves?, in: Research Activities in Atmospheric and Oceanic Modelling, edited by: Coté, J., 34, WMO/TD No. 1220, 7, 37-38, 2004. von Storch, H., Langenberg, H., and Feser, F.: A spectral nudging technique for dynamical downscaling purposes, Mon. Weather Rev., 128, 3664-3673, 2000.

Vukicevic, T. and Errico, R.: The influence of artificial and physical factors upon predictability estimates using a complex limitedarea model, Mon. Weather Rev., 118, 1460-1482, 1990. 